\title{
ANALYTICAL VERSUS NUMERICAL CALCULATIONS OF PHYSICAL PROBLEMS. THE BENEFITS OF ITS COMBINATION
}

\author{
H.-D. LIESS and A. ILGEVIČIUS \\ University of the Federal Armed Forces in Munich \\ Werner-Heisenberg-Weg 39 \\ 85579 Neubiberg, Germany \\ E-mail: \{HDLiess; Audrius. Ilgevicius\}@UniBw-Muenchen.de
}

Received September 9, 2003; revised November 10, 2003

\begin{abstract}
The disadvantage of the pure application of numerical approaches, however, is the fact, that the physicals laws behind are not so easy to visualize, the results art not so easy to generalize, and the storage of the information requires mostly an extensive amount of data. This paper would like to show at some examples the advantages of the combination of both methods. The key part of this approach is the calculation of the heat transfer by the Finite Volume Method (FVM) and the approximation of the calculated data by the so-called "simplified equations". These simplified equations were received by analytical solutions of the basic heat conduction equation. The required adaptation of the numerical results was done with properly adapted fitting algorithms on the basis of the elaborated analytical solutions, a process which was leading to an enormous reduction of data. As a result it became possible to describe the applied tasks by a few characteristic constants.

Another approach for an analytical solution with a numerical calculation process is the determination of the so-called "properties of mixed magnitudes". As an example this principle has been applied for the numerical calculation of electrical multi conductor containing cables. This process allowed the prediction of the thermal behavior of any cable harness with the required precision.
\end{abstract}

Key words: mathematical modeling, heat transfer, electrical cables

\section{INTRODUCTION}

The task for the example taken here is to determine the induced heating up of the electrical wire harness as a function of the electrical current and the applied time. The main difficulties of many similar cases, like heat transfer, 
are due the following remarks:

- most equations cannot be solved analytically, due to heat dependence on various constants,

- if the equations are, however, solved numerically, the calculation requires too much time.

Finite difference and finite element methods for thermal analysis of electrical cables were implemented by Hiranandani [2] and Tarasiewicz [5]. Developments of such algorithms require a lot of time investments and for the industry customers are not acceptable. Therefore there is a need to find simpler and easy - implement methods with a good accuracy and reliability ensuring results for engineering applications. This paper tends to present such a method for thermal analysis of electrical wires and cables based on analytical-numerical solutions of the heat transfer equation.

In the following sections the basic physical laws and its combination of numerical and analytical methods will be given for the example of the heat transfer in electrical cables for mobile application.

\section{THE MATHEMATICAL MODEL}

The basic equation describing the heat transfer has the following conservative form:

$$
\operatorname{div}(\lambda(T) \operatorname{grad} T)+p(T)=\gamma(T) \frac{\partial T}{\partial t},
$$

where: $\gamma(T)$ is the heat capacity $\left(W s / m^{3} K\right), \lambda(T)$ is the heat conductivity $(W / m K), p(T)$ is the heat generation (Joule's) and heat losses (into environment) $\left(W / m^{3}\right), t$ is the time $(s), T$ is the temperature $(K)$.

For round wires the heat conduction equation may be separated into two one dimensional parts due to the fact, that for practical applications the length of it is big compared to the diameter and therefore the heat transfer in radial direction is faster, than in axial direction.

For the treatment of the axial direction the heat conduction equation (2.1) may be simplified to:

$$
\frac{\partial}{\partial x}\left(\lambda(T) \frac{\partial T}{\partial x}\right)+p(T)=\gamma(T) \frac{\partial T}{\partial t} .
$$

For the treatment of the radial direction we take into account the rotational symmetry, therefore the heat conduction equation may be simplified to:

$$
\frac{1}{r} \frac{\partial}{\partial r}\left(r \lambda(T) \frac{\partial T}{\partial r}\right)+p(T)=\gamma(T) \frac{\partial T}{\partial t} .
$$

Both equations can be treated separately. The following example will be restricted to the radial direction only. 


\section{ANALYTICAL TREATMENT OF THE CONDUCTOR TEM- PERATURE}

\subsection{Transient state regime for a non-insulated conductor}

The first chosen example should be calculated is a conductor without isolation (e.g. blank copper wire) in air. It can be shown, that the temperature difference of the conductor in the radial direction is negligible. Therefore the radial temperature decay in the conductor can be neglected, i.e. $\frac{\partial T}{\partial x}=0$, and therefore one has

$$
p(T)=\gamma(T) \frac{\partial T}{\partial t}
$$

The term $p(T)$ describes Joule's heat generation and heat losses into environment and it can be written as follows:

$$
p(T):=p_{E}-q_{T} \frac{O}{V}=\rho(T) \frac{I^{2}}{A^{2}}-\alpha(T) \frac{u}{A} \Delta T
$$

where $\alpha(T)$ is the surface heat dissipation factor $\left(W / m^{2} K\right), \Delta T=T-T_{U}$ is the temperature difference between surface and environment $(K), p_{E}$ is the electrically generated heat $\left(W / m^{3}\right), q_{T}$ is the temperature difference induced heat dissipation through surface $\left(W / m^{2}\right), u$ is the circumference $(m), A$ is the cross-section $\left(m^{2}\right), I$ is the current $(A), O=u l$ is the surface $\left(m^{2}\right), V=l A$ is the volume $\left(m^{3}\right)$.

The problem is now that all four applied "constants" $\alpha(T), \gamma(T), \lambda(T)$, and $\rho(T)$ are temperature dependant. The differential equation (3.1) can be solved analytically, if the following simplifications are applied:

$$
\begin{aligned}
& \alpha(T)=\left(\frac{\alpha_{d}}{\sqrt{d}}+\alpha_{T} \sqrt[6]{\Delta T}\right)^{2}+\varepsilon \sigma\left(\frac{T^{4}-T_{U}^{4}}{\Delta T}\right) \approx \alpha \\
& \gamma(T) \approx \gamma_{0}\left(1+\alpha_{\gamma} \Delta T\right) \\
& \rho(T)=\rho_{0}\left[1+\alpha_{\rho} \Delta T+\beta_{\rho}(\Delta T)^{2}+\ldots\right] \approx \rho_{0}\left(1+\alpha_{\rho} \Delta T\right)
\end{aligned}
$$

The solution of equation (3.1) with assumptions (3.2) and (3.3) results in the differential equation:

$$
d t=\frac{\gamma_{0}\left(1+\alpha_{\gamma} \Delta T\right) d T}{\frac{\rho_{0} I^{2}}{A^{2}}\left(1+\alpha_{\rho} \Delta T\right)-\frac{\alpha u \Delta T}{A}}=\frac{\gamma_{0} A^{2}\left(1+\alpha_{\gamma} \Delta T\right) d T}{\rho_{0} I^{2}\left[1+\left(\alpha_{\rho}-\frac{\alpha u A}{\rho_{0} I^{2}}\right) \Delta T\right]}
$$

Integration from $t=0$ till $\infty$ leads finally to the temperature increase with time:

$$
\Delta T=\frac{1}{\frac{\alpha u A}{\rho_{0} I^{2}}+\alpha_{\gamma}-\alpha_{\rho}}\left(1-\exp \frac{\gamma_{0} A^{2}}{\alpha u A-\left(\alpha_{\rho}+\alpha_{\gamma}\right) \rho_{0} I^{2}} t\right)=\Delta \hat{T}\left(1-\exp \frac{t}{\tau}\right)
$$


where the final conductor temperature $\Delta \hat{T}$ after an infinite period of time is given as:

$$
\Delta \hat{T}=\frac{1}{\frac{\alpha u A}{\rho_{0} I^{2}}+\alpha_{\gamma}-\alpha_{\rho}}
$$

and the conductor heating up time $\tau$ :

$$
\tau=\frac{\alpha u A-\left(\alpha_{\rho}+\alpha_{\gamma}\right) \rho_{0} I^{2}}{\gamma_{0} A^{2}}
$$

with $u=\pi d$ and $A=\pi d^{2} / 4$.

\subsection{Steady state regime for an insulated conductor}

Since for a metallic conductor the radial temperature decay can be neglected the calculation of the temperature behaviour can be restricted to the temperature drop in the insulation material and heat convection to the ambient.

For the steady state regime and no heat generation in the insulation the following terms in the equation (2.3) becomes zero:

$$
\frac{d T}{d t}=0, p(T)=0
$$

Using the assumption that the heat dissipation factor $\alpha$ into air, the heat conductivity $\lambda$ of the isolation material, and the electrical resistivity $\rho$ are all constant, the conductor temperature can be calculated by integrating the following equation:

$$
\frac{d^{2} T}{d r^{2}}+\frac{1}{r} \frac{d T}{d r}=0
$$

Taking into consideration boundary conditions given in the publication [4] we get the solution of temperature distribution in a cylindrical insulated conductor:

$$
\Delta T=\frac{4 \rho I^{2}}{\pi^{2} d_{1}^{2}}\left(\frac{1}{\alpha d_{2}}+\frac{1}{2 \lambda} \ln \frac{d_{2}}{d_{1}}\right)
$$

\section{NUMERICAL TREATMENT OF THE CONDUCTOR TEM- PERATURE}

The numerical algorithm is described in detail in the publication [4]. Using the implicit finite volume method, we obtain finite volume scheme approximated by central differences. In time, differential equation (4.1) is written implicitly. 


\subsection{The mathematical model}

We shall consider the partial differential equation:

$$
\frac{1}{r} \frac{\partial}{\partial r}\left(r \lambda(T) \frac{\partial T}{\partial r}\right)+p(T)=\gamma(T) \frac{\partial T}{\partial t} .
$$

When constructing the numerical scheme we make several assumptions. First, we assume that the heat conductivity of both conductor and insulation is constant, since temperature drop inside of the cable is only $2-4 \%$. Secondly, we assume that the change of electrical resistance because of temperature increase is a linear function. This assumption is correct for a reasonable temperature range $\left(20-150^{\circ} \mathrm{C}\right)$.

We have the following conditions:

1. Continuity conditions on surfaces $r=r_{i}, i=\overline{1, N-0.5}$ for the temperature and fluxes:

$$
\left\{\begin{array}{l}
\Delta T_{i}\left(r_{i}, t\right)=\Delta T_{i+1}\left(r_{i}, t\right), \\
-\left.\lambda_{i} \frac{\partial \Delta T_{i}\left(r_{i}, t\right)}{\partial r}\right|_{r=r_{1}}=-\left.\lambda_{i+1} \frac{\partial \Delta T_{i+1}\left(r_{i}, t\right)}{\partial r}\right|_{r=r_{1}}
\end{array}\right.
$$

2. Boundary conditions on surfaces $r=r_{0}$ and $r=r_{N}$ :

$$
\left\{\begin{array}{l}
\lim _{r \rightarrow 0} r \lambda_{1} \frac{\partial \Delta T_{1}\left(r_{0}, t\right)}{\partial r}=0 \\
-\left.\lambda_{N} \frac{\partial \Delta T}{\partial r}\right|_{r=r_{N}}=\alpha(d, \Delta T)\left(T_{N}\left(r_{N}, t\right)-T_{e n v}\right)+\varepsilon \sigma\left(T_{N}^{4}\left(r_{N}, t\right)-T_{e n v}^{4}\right) .
\end{array}\right.
$$

\subsection{The finite volume method}

Using the implicit finite volume method, we obtain the following numerical scheme, where the integrals are approximated by central differences:

$$
\begin{gathered}
\left\{\begin{array}{r}
-\frac{r_{1 / 2} \lambda_{0.5}}{\Delta r_{1 / 2}}\left(\Delta T_{1}^{n}-\Delta T_{0}^{n}\right)+\frac{\Delta r_{0} r_{1 / 2} \gamma_{0.5}^{n}}{\Delta t}\left(\Delta T_{0}^{n}-\Delta T_{0}^{n-1}\right) \\
=\Delta r_{0} r_{1 / 2} p_{0}, \quad i=0,
\end{array}\right. \\
\left\{\begin{array}{c}
-\frac{r_{i+1 / 2} \lambda_{i+1 / 2}}{\Delta r_{i+1 / 2}}\left(\Delta T_{i+1}^{n}-\Delta T_{i}^{n}\right)+\frac{r_{i-1 / 2} \lambda_{i-1 / 2}}{\Delta r_{i-1 / 2}}\left(\Delta T_{i}^{n}-\Delta T_{i-1}^{n}\right) \\
+\frac{\Delta r_{i} r_{i} \gamma_{i}^{n}}{\Delta t}\left(\Delta T_{i}^{n}-\Delta T_{i}^{n-1}\right)=\Delta r_{i} r_{i} p_{i}, \quad 1.5<i<N, \\
\alpha\left(T_{N}^{n}-T_{e n v}\right)+\beta\left(\left(T_{N}^{n}\right)^{4}-T_{e n v}^{4}\right)+\frac{r_{N-1 / 2} \lambda_{i-1 / 2}}{\Delta r_{N-1 / 2}}\left(\left(T_{N}^{n}\right)^{4}-T_{N-1}^{n}\right) \\
+\frac{\gamma_{i}^{n}(T) \Delta r_{N}}{2 \Delta t}\left(\Delta T_{N}^{i}-\Delta T_{i}^{n-1}\right)=\frac{1}{2} r_{N} \Delta r_{N} p_{N}, \quad i=N .
\end{array}\right.
\end{gathered}
$$


The Newton-Raphson iteration Method [2] is used to linearize the equations.

\section{SELECTION OF THE "SIMPLIFIED EQUATIONS" FOR DA- TA REDUCTION}

The key point of this section is the data reduction of the received numerical calculated values. This is performed by fitting the calculated values with the so-called "Simplified Equations" in the temperature range of interest. The following values are calculated and saved as functions of the current:

1. - Final temperature difference of the conductor $\Delta T(I)$ for $I \leq I_{0}$.

- Heating up time of the conductor $t(I)$ for $I \geq I_{0}$.

2. Voltage drop per length (field strength) in the conductor $E(I)$.

As a result of this procedure, the three so-called "Simplified Equations" are elaborated, which describe the thermo-electrical behaviour sufficiently precise in the current range of interest.

For $I \leq I_{0}$ the final temperature difference is given by:

$$
\Delta T\left(I \leq I_{0}\right)=a I+b I^{2} ;
$$

the heating up time is given by:

$$
t\left(I \geq I_{0}\right)=\tau \ln \frac{I^{2}}{I^{2}-I_{0}^{2}} ;
$$

and the voltage drop per length (field strength) is defined as:

$$
E=I R=I R_{0}\left(1+\alpha_{\rho} \Delta T+\beta_{\rho}\left(\Delta T^{2}\right)\right),
$$

where $R_{0}$ is the resistance of the wire $(\Omega), \alpha_{\rho}$ is the linear temperature coefficient of copper resistance $(1 / K), \beta_{\rho}$ is the square temperature coefficient of copper resistance $\left(1 / K^{2}\right)$.

\section{Determination of the "Characteristic Wire Values" by Fitting}

The "Simplified Equations" contain the following four so-called "Characteristic Wire Values" $I_{0}, a, b, \tau$, which together describe the thermo-electrical behaviour of each conductor sufficiently precise in the current range of interest. These values are obtained by fitting the "Simplified Equations" (5.1-(5.3) with the numerical results (see [4]).

\section{MULTI WIRE CABLE}

The calculation of the single wires is the basis for the calculation of multi wire cables. Hereby the formulas for a single wire core may be used for 
the calculation of a multi-wire core. The main problem is, however, that this core consists of non-homogeneous material, which cannot be described analytically nor easily calculated by numerical methods. The solution of this special problem, which is explained in this section in detail, was to consider the non-homogeneous cable core as "quasi-homogeneous" and to apply the same solutions, which were used for the single wire cable already.

By applying this assumption, the calculation problem will be reduced to the elaboration of the thermo-electrical properties, called here: "Mixed Constants", of the quasi-homogeneous cable core. The subject of this section is to discuss the possible approaches and their range of validity.

\subsection{Analytical Solution}

\subsubsection{Assumption of a homogeneous conductor}

In analogy to a single isolated conductor (see Fig.1a) a multi-isolated cable conductor (see Fig.1b) will be considered as an isolated "mixed" conductor in the frame of this section.

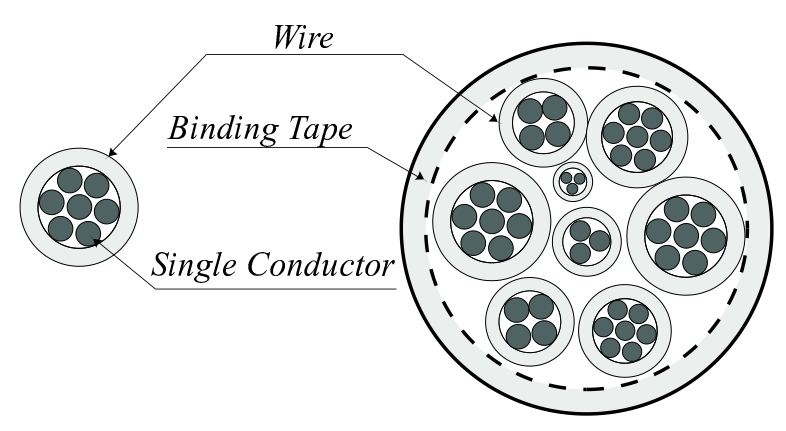

a)

b)

Figure 1. Isolated single (a) and isolated multi cable conducting core (b) .

Isolated single conducting core (isolated wire equation (3.8)) with only an additionally term describing the temperature drop in the conductor is described by:

$$
\Delta \hat{T}=\frac{p}{\pi}\left(\frac{1}{\alpha d_{2}}+\frac{1}{2 \lambda} \ln \frac{d_{2}}{d_{1}}\right),
$$

for an isolated mixed conducting core (consisting of several isolated wires) this formula transforms to the expression:

$$
\Delta \hat{T}=\frac{p}{\pi}\left(\frac{1}{\alpha(D+2 S)}+\frac{1}{2 \lambda_{I}} \ln \left(1+\frac{2 S}{D}\right)+\frac{1}{4 \lambda_{L}}\right),
$$

here $\lambda_{I}, \lambda_{L}$ are the heat conductivity of isolation and of mixed conductor $(W / m K), d_{1}, d_{2}$ are diameter of conductor and of isolation $(m), D$ is the 
diameter of the cable without isolation $(m), I$ is the current $(A), p=\sum_{1}^{n} p_{n}$ describes the electrical power per length $E I$, i.e. a sum of all single wires $(W / m), S$ is the thickness of isolation $(m)$.

\subsubsection{Calculation of a quasi-homogeneous conductor (Model 1).}

The next step is the transformation of an isolated mixed conducting core (consisting of several isolated wires) into a structure, which can be analytically or numerically calculated easily. The way proposed here is the conversion of the round isolated wires into a square ones with the same conductor-, isolation-, and air cross section, as before (see Fig. 2).

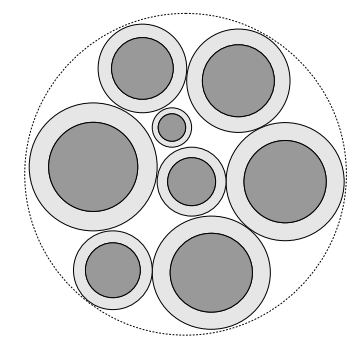

a)

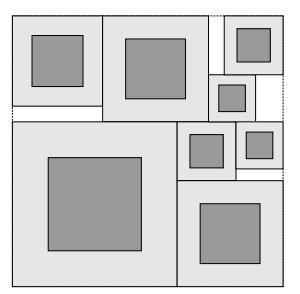

b)

Figure 2. Transformation of isolated round conductors (a) in squares of same area (b).

This structure can be now calculated easily as a thermal serial-parallel switched model of similarly covered areas. In order to simplify the calculation, the whole solid material was separated from the air and combined in three blocks. The influence of the much less heat conducting air will be considered later with the so-called "Filling Factor".

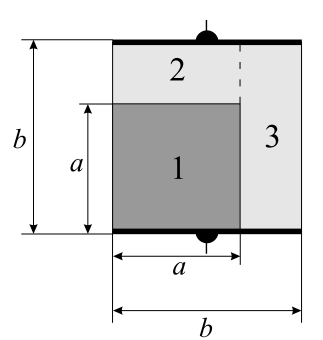

a)

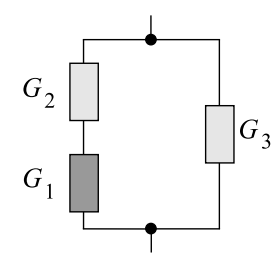

b)

Figure 3. Determination of the mixed area conductivity: (a) assembly, (b) circuitry.

For long (compared to their thickness) wires, the whole material can be treated two-dimensionally with a so-called "area conductivity" $\lambda l$ which has 
the dimension $W / K$ and which is proportional to the known heat conductivity $\lambda$. The heat conductance $G$ is given by $G=\frac{\lambda l x}{y}$ and for each block given in Fig.3 we obtain

$$
G=\lambda l, \quad G_{1}=\lambda_{1} l, \quad G_{2}=\lambda_{2} l \frac{a}{b-a}, \quad G_{3}=\lambda_{2} l \frac{b-a}{b} .
$$

The serial connection of blocks 1 and 2, and a parallel to 3 leads to the following heat conduction in $y$-direction

$$
G=\frac{G_{1} G_{2}}{G_{1}+G_{2}}+G_{3} .
$$

Finally we obtain a "Mixed Material Equation" of the following form

$$
\lambda=\lambda_{2}\left(\frac{1}{\frac{\lambda_{2}}{\lambda_{1}}+\frac{b}{a}-1}-\frac{a}{b}+1\right),
$$

where the heat conductances are replaced by their heat conductivities. Here $\lambda$ is the radial thermal mixed conductivity $(W / m \cdot K), a$ is the length of heat conductor $1(\mathrm{~mm}), b$ is the length of mixed heat conductors 1 and $2(\mathrm{~mm})$.

\subsubsection{Calculation of the relationship b/a (Model 1).}

The next step is to determine the relationship of $b / a$ which is calculated from the area $a^{2}$ of the material 1 (which may be the cross section of the conductor) and the whole area $b^{2}$ of the materials 1 and 2 (which may be the cross section of the conductor and the isolator). Since the conductor consists of single wire veins with air in between, the real conduction cross section $a^{2}$ has still to be multiplied with the so-called filling factor $f$, which is the relationship of the real conducting cross section to the cross section to be determined by its measured diameter: $A_{1}=a^{2} f$. The cross section of the conductor and the isolator together results in:

$$
\frac{A_{1}}{f}+A_{2}=b^{2}
$$

from which finally $b / a$ can be calculated, whereby the areas $A_{2}$ and $A_{1}$ may be replaced by the diameters of the conductor $d$ and core leads $\delta$ :

$$
\frac{b}{a}=\sqrt{\left(\frac{f A_{2}}{A_{1}}+1\right)}=\sqrt{\frac{f \sum_{1}^{i} d_{i}^{2}}{\sum_{1}^{i} n_{i} \delta_{i}^{2}}}=\sqrt{\frac{f}{\Sigma}} .
$$




\subsubsection{Thinning model (Model 2).}

The Model 1 described in section (6.1.2) by the equation (6.3) is only valid for materials with similar heat conductivity. If one partner diverts as far as air compared to copper it is not applicable any more. In this case the assumption is made, that the conductor consists of two different conducting materials, which are switched in parallel as follows: $G=G_{a}+G_{b}$.

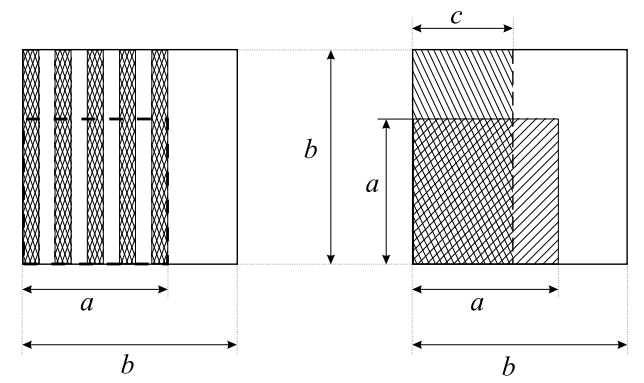

Figure 4. Volume change due to empty spaces, in accordance with the filling factor $f$ or $F$.

In accordance with Fig. 4 the heat conductivities can be calculated as follows:

$$
G=\lambda, \quad G_{a}=\lambda_{a} \frac{c}{b}, \quad G_{b}=\lambda_{a} \frac{b-c}{b},
$$

where $\lambda$ is the mixed heat conductivity $(W / m K), \lambda_{a}, \lambda_{b}$ are heat conductivity of area $a^{2}$ and $b^{2}$, respectively $(W / m K), a, b$ are virtual length of all conductors and of mixed conductor $(\mathrm{mm}), c$ is the virtual length $c / b$ of $b^{2}$ $(\mathrm{mm})$. Replacing a square element by two rectangular elements with different heat conductivity, (see Fig.4) leads to the mixed heat conductivity: $\lambda=\lambda_{a} \frac{c}{b}+\lambda_{b} \frac{b-c}{b}$. Using the filling factor $f=\frac{c}{b}$ for the air between veins in a wire, and $F=\frac{b-c}{b}$ for the air between wires in a cable gives the thinning equations: $\lambda=\lambda_{a} f+\lambda_{b}(1-f) \approx \lambda_{a} f, \lambda=\lambda_{a} F+\lambda_{b}(1-F) \approx \lambda_{a} F$.

\subsubsection{Combination of the models}

Assuming the application of the Model 1 is more suited for isolation material and the Model 2 is more suited for air between the conductor, the two equations can be combined as follows. In this case the heat conductivity $\lambda$ of the mixed material without air can be replaced by the heat conductivity $\lambda F$ of the mixed material with air. In case the conductor material has much higher heat conductivity than the isolation material, the equation may be simplified even further, e.g. for $\lambda_{1} f>>\lambda_{2} F$ we obtain

$$
\lambda=\lambda_{2} F\left(1+\frac{1}{\sqrt{\frac{f}{\Sigma}}+\frac{\lambda_{2}}{\lambda_{1} f}-1}-\frac{1}{\sqrt{\frac{f}{\Sigma}}}\right) \approx \lambda_{2} F\left(1+\frac{1}{\frac{f}{\Sigma}-\sqrt{\frac{f}{\Sigma}}}\right) .
$$




\subsection{Electrical load of conductors in standstill air}

\subsubsection{Realization of Practical Measurements}

In the same way as performed for single isolated wires the results of this particular calculation had to be controlled by high precision automatic measurement equipment at room temperature. In order to compare the current dependence on the temperature calculated with the formulas the current was increased and decreased in about 10 steps and the temperature measured at each step after reaching the steady state. The temperature values were received with two independent principles:

1. Via electrical temperature dependant resistance of the conductor material.

2. Via thermo-couples (for control).

6.2.2. Matching of measured results with numerical results.

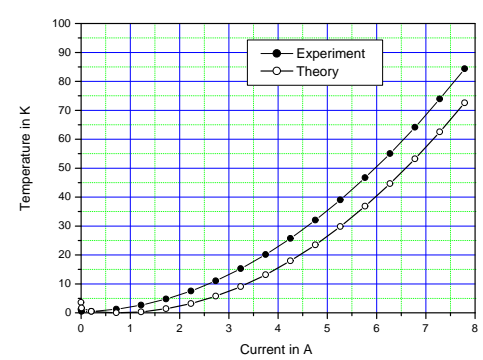

a)

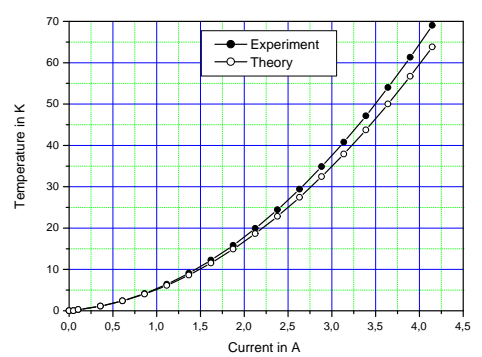

b)

Figure 5. Experimental versus theoretical results of different cable bundle size: (a) cable bundle consist of 10 wires, and (c) cable bundle consists of 40 wires.

An important step is also here the fitting of the calculated results with the measured results (Fig. 5) by the variation of the material data to tune the calculation procedure (see section 6 ) in order to prove the general validity of the applied mixture calculation for physical properties. It turned out, that the systematic differences between calculated and measured results can be compensated by proper application of the elaborated equations and a small correction factor if necessary. In the Fig. 5 the temperature behaviour of different size of cable bundles calculated by the method are presented. Theoretical data are compared with experiment results. In all cases (Fig.5 a,b,c) there exists a disagreement between both results. This is explained by the difficulty to calculate precise the heat conductivity coefficient of the cable bundle. In reality it is very difficult to model properly the cable bundle, that coincides geometrically the real model. Thus, this non-identity between the two models causes the error in the heat conductivity coefficient. Also, the radiation is the reason of the errors, since for large diameters of cable bundles up to $30 \%$ of heat is dissipated by the radiation. Therefore it is also very important to determine correctly the emissive coefficient too. 


\section{CONCLUSIONS}

The advantage of combining both analytical and numerical calculation methods is the possibility to reduce analytically not solvable problems to equations, which describe the required task within a limited range of parameters sufficiently precise. It is only necessary to control the validity of this simplification carefully by measurement results. In most cases the systematic errors can be compensated.

For some investigated cases the proposed "Simplified Equations", "Characteristic Wire Values", and "Mixed Materials Equations" described the situation sufficiently precise and therefore they can be fed in a computerized design tool for the fast calculation of multi wire cable dimensions.

\section{REFERENCES}

[1] VDI-Wärmeatlas, 8. Auflage, Springer-Verlag, Berlin, New York.

[2] A. Haskew, Tim, Regina F. Carwile and L. Grigsby, L. An algorithm for steady-state thermal analysis of electrical cables with radiation by reduced Newton-Raphson techniques. IEEE Transactions on power delivery, 9(1), January 1994.

[3] Ajit Hiranandani. Calculation of conductor temperatures and ampacities of cable systems using a generalized finite difference model. IEEE Transactions on power delivery, 6(1), 15 - 21, January 1991.

[4] A. Ilgevičius and H.-D. Liess. Calculation of the heat transfer in cylindrical wires and electrical fuses by implicit finite volume method. Mathematical Modelling and Analysis, 8(3), $217-227,2003$.

[5] E. Tarasiewicz and et al. Calculation of temperature distributions within cable trench Backfill and Surrounding Soil. IEEE Transactions on power apparatus and systems, PAS-104(8), 1973 - 1978, August 1985.

Kai kuriu fizikos uždavinių sprendimas analitiniais-skaitiniais metodais bei šiu metodų derinio pranašumai

H.D. Liess, A. Ilgevičius

Darbe nagrinejjamas analitinis metodas, temperatūros pasiskirstymo elektros laiduose bei ju pluoštuose uždaviniams spręsti. Analitinis metodas yra pritaikytas šilumos laidumo koeficientams paskaičiuoti daugiasluoksnejje medžiagoje - elektros laidu pluošte.Temperatūros pasiskirstymui atskirame elektros laidininke paskaičiuoti yra pritaikytas baigtinių tūrių metodas. Turint tikslias atskiro laidininko temperatūros vertes, toliau laidų pluošto temperatūrų vertes galima skaičiuoti analitiškai, įvedus proporcingumo koeficientus šilumos laidumo dydžiui rasti. Tokia procedūra duoda galimybę gauti efektyvų algoritmą, skirtą spręsti šilumos pernešimo uždavinius atskiruose laiduose tiek ju pluoštuose su skirtingais skerspjūviais. 